\title{
Between Two Worlds
}

\section{Medical Student Perceptions of Humor and Slang in the Hospital Setting}

Genevieve Noone Parsons, MD, Sara B. Kinsman, MD, PhD, Charles L. Bosk, PhD,

Pamela Sankar, PhD, Peter A. Ubel, MD

OBJECTIVE: Residents frequently use humor and slang at the expense of patients on the clinical wards. We studied how medical students react to and interpret the "appropriateness" of derogatory and cynical humor and slang in a clinical setting.

DESIGN: Semistructured, in-depth interviews.

SETTING: Informal meeting spaces.

PARTICIPANTS: Thirty-three medical students.

MEASUREMENTS: Qualitative content analysis of interview transcriptions.

MAIN RESULTS: Students' descriptions of the humorous stories and their responses reveal that students are able to take the perspective of both outsiders and insiders in the medical culture. Students' responses to these stories show that they can identify the outsider's perspective both by seeing themselves in the outsider's role and by identifying with patients. Students can also see the insider's perspective, in that they identify with residents' frustrations and disappointments and therefore try to explain why residents use this kind of humor. Their participation in the humor and slang-often with reservations - further reveals their ability to identify with the perspective of an insider.

CONCLUSIONS: Medical students describe a number of conflicting reactions to hospital humor that may enhance and exacerbate tensions that are already an inevitable part of training for many students. This phenomenon requires greater attention by medical educators.

KEY WORDS: medical education; ethics; qualitative; interview; medical students; medical humor.

J GEN INTERN MED 2001;16:544-549.

C amuel Shem's popular The House of God, ${ }^{1}$ which $\checkmark$ described the culture of the medical intern and popularized such terms as "gomer," intensified concern

Received from the Center for Bioethics, University of Pennsylvania School of Medicine, Philadelphia, Pa (GNP, SBK, CLB, PS); the Department of Pediatrics, Johns Hopkins University, Baltimore, Md (GNP); the Craig-Dalsimer, Division of Adolescent Medicine, The Children's Hospital of Philadelphia, Philadelphia, $\mathrm{Pa}$ (SBK); the Department of Sociology, University of Pennsylvania, Philadelphia, Pa (CLB); and the Division of General Internal Medicine, University of Michigan School of Medicine (PAU) and the Veterans Affairs Medical Center (PAU), Ann Arbor, Mich.

Address correspondence and reprint requests to Dr. Ubel: University of Michigan Health System, 300 North Ingalls, Room 7C27, Ann Arbor, MI 48109-0429 (e-mail: paubel@umich.edu). about the appropriateness of cynical slang. Authors who have attempted to understand the development of this darkly comedic argot note that derogatory humor and slang can serve important functions in the psychological wellbeing and survival of the house staff. ${ }^{2-4}$ Beyond that, other authors point to a sociologic literature indicating that all work groups develop a "backstage" language not meant to be understood by outsiders. ${ }^{5-7}$ Critics of this genre of humor believe that labeling it as a coping mechanism does not justify behavior which often belittles and degrades patients. $^{8,9}$

Despite these debates, however, few have studied the effect that such humor has on medical students as they mature into physicians. We know that medical students encounter dilemmas created by their unique novice status within the medical hierarchy, and that some medical students specifically identify hospital humor as ethically problematic. ${ }^{10}$ We do not know, however, the answer to two key questions: How do students react to the humor and slang used by resident physicians and other students? And, over time, how do they interpret the "appropriateness" of derogatory or cynical humor and slang in the clinical setting?

To address these two questions, we conducted indepth interviews of 2 groups of medical students - those beginning clinical rotations and those 1 year into their clinical rotations - and asked them to comment about the hospital humor they had observed.

\section{METHODS}

\section{Study Site and Population}

The interviews were conducted between January 1997 and May 1997 at a major northeastern medical school. At this institution, students begin their core clinical clerkships in the middle of their second year and complete their subinternships (when the students assume patient responsibilities roughly equivalent to an intern's) in the middle of their third year.

\section{Sampling and Subjects}

We used judgment sampling, choosing subjects purposefully to assure that we sampled the range of age, gender, and clerkship experience. ${ }^{11}$ We asked 40 students (chosen through the school's list of students registered for Spring rotations) to participate in an interview about their experiences in the clinics. Of these, 4 students declined the interview, and 3 students who agreed were not interviewed 
secondary to scheduling conflicts. We interviewed 33 medical students, 16 women and 17 men. Fifteen interviewees were second-year students ("clerks") who had recently completed 1 or 2 months of their first core clinical clerkships in either medicine (5), pediatrics (4), or surgery (6). Eighteen interviewees were third-year students ("subinterns") who had recently completed subinternships in medicine (9), pediatrics (7), or surgery (2). The setting of each interview depended on the convenience of the student, and included the medical student lounge, the medical student office, and the student's home.

\section{Interview Design}

We conducted semistructured, in-depth interviews, a technique that is particularly useful for capturing social experience from the subject's point of view. ${ }^{12}$ The interview was pilot tested and refined on the basis of 14 interviews (not included in the 33 interviews reported here). The 33 study interviews, ranging from 30 minutes to 1 hour in length, were audiotaped and transcribed. The interviewer (the first author, who at the time was a medical student) first asked students to discuss "situations in the clinics or hospital in which humor was used," without any specific request for examples of appropriate or inappropriate humor. Follow-up questions to clarify content or meaning were asked for stories involving humor about patients. The interviewer also asked subjects to discuss the appropriateness of specific slang terms commonly used in the clinical setting, including "gomer," "train wreck," and "wheezer."

\section{Data Analysis}

All transcripts were entered into the qualitative software program, NUD*IST. All of the transcripts were read by at least 3 of the investigators, who met periodically to discuss themes that emerged during the readings. Each interview was then reread by the first author and text segments were categorized into the emergent themes previously identified.

\section{RESULTS}

Students had complex reactions to the humor used on the hospital wards, as well as divergent opinions about its appropriateness. To best describe their initial responses and opinions, we have used a construct of the "outsider" versus the "insider" perspective. Some reactions showed students assuming an outsider's perspective of the humor. Other reactions showed them taking an insider's perspective. In what follows, the students' comments illustrate these different viewpoints.

\section{The Outsider's Perspective}

Students' responses to hospital humor, and many of their descriptions of their nonparticipatory role in the humor, made it clear that they could take the perspective of an outsider to the medical culture.

Students See Themselves as Outsiders. Five of the 33 students spontaneously reported that they were expected to assume the role of observer, and not main actor, in the humorous stories. As a 24-year-old male medicine clerk said:

I think people expect students to be a little bit more idealistic, a little bit less cynical. Some of that is accepted at the intern level, I believe, to a greater extent than at a student level.

A 24-year-old male medicine subintern reported that a senior physician (an "attending physician") was displeased when a fellow student called a patient a "brick" (a patient who has been in the hospital a long time and is not likely to be discharged soon). The attending did not think that the student should be so jaded this early in his career. In addition to this interview, 2 other students reported that an attending explicitly told students not to participate in the humor.

Students' identification with the outsider's perspective was emphasized by the fact that 7 perceived that the humor was at their expense. A 25-year-old female pediatrics clerk said:

People on the team use humor to make fun of other people on the team, especially medical students... A lot of times, people are laughing at you and you don't know why they're laughing.

As a 28-year-old male medicine subintern explained:

[The humor] largely emanated from a group of 2 or 3 residents. And as the medical student, the first time ever in the clinics, it wasn't really my position at all to say things like that in the first place. But the least I could do was laugh.

Identification with the Patient's Perspective. Six students demonstrated that they had an outsider's appreciation of the patient's perspective. A 23-year-old pediatrics clerk showed identification with and empathy for the patient in the following story:

We were talking about a child whose parents had 8 other children, and this was the ninth who was in the hospital. The 8 other children were all being followed by genetics because of a chromosomal abnormality. Somebody said what we were all thinking: "What were the parents thinking, to keep on having children?" And then someone else [a resident] said, "Well, practice makes perfect!" I felt badly about laughing because... it just seems like a really difficult situation to be in. Then I thought, well, maybe that is part of their motivation. Maybe they just wanted to keep on trying and hoping that they would have a child without that kind of abnormality.

A 24-year-old male medicine clerk also showed an understanding of the patient's, or outsider's, perspective as he related his opinion of the term "brick" (defined above):

I just think that when people use these terms, they're directing them against the patient when it's not really 
the patient's fault. I mean, a person isn't a brick. There are rare cases of malingering. I don't think I saw any patient that I followed closely who was clearly malingering, as in making up symptoms just for the sake of being in the hospital. Most of the "bricks" were there not on their own account, but because there were administrative problems with getting them discharged.

\section{Understanding the Insider's Perspective}

Despite their ability to appreciate the view of an outsider, students can also see things from the perspective of insiders. Most commonly, they said that this humor helped residents cope with the frustrations of their job: "difficult" or unappreciative patients (15), a demanding work load and chronic sleep deprivation (18), and medical efforts that often do not result in improved patient outcomes (12). Students also pointed out that humor helps physicians cope with sadness, illness and death (11), and having to hurt people (4). Finally, students noted the inclusionary nature of the humor and jargon, which allows one to fit into the clinical team and the medical profession (9).

\section{“No Longer Inconceivable;" Identification with Residents'} Frustrations. Twenty-four of the 33 students said that they could understand why the residents used derogatory humor and slang. Other students explained that their own experiences helped them not only to understand, but to identify with the residents. One 25-year-old medicine subintern's experience is a powerful example of how students' own frustrations help them identify with the “insider's" viewpoint.

[The residents were] talking about older patients as toads and frogs and gomes [a derivative of "gomer," an acronym spelled out by "Get Out of My Emergency Room"- typically refers to an elderly, debilitated patient whom the resident does not want to care for]. I had never heard patients talked about in that way. And just going from the classroom to the clinics with all these ideals of what doctors were suppose to be like... It was 20 [physicians] sitting at breakfast together like a big football team and talking about patients in a way that was very disappointing.

The same student went on to point out that one clinical service referred to its patients as "The Toad Service."

They told me someone had named it that a couple of months ago because the patients are all just old people in contractures [bent, weak limbs], and they looked like toads. Which is pretty revolting... It was appalling to me. I was so shocked at the way doctors talked about people in the beginning. But having just finished a month of being that tired and sleep deprived, and being up all night for really stupid things, I can see where the frustration comes from. I still don't think it's right, but I can understand it a little. Now it's no longer inconceivable to me why people talk that way about patients and families.

After discussing terms like gomer and rock (a term synonymous with "brick"), a 25-year-old pediatrics subintern expressed his ability to identify with the residents, based on recent experiences:

I'm not condoning it, and I hope I never do it. But having experienced just one month of a sub-I... if an entire year of internship is like that, I can very easily see how you come to the end of your rope. I remember sitting in Bioethics the week before my sub-i, and the question was raised: "You have just left the hospital, your beeper goes off, and what do you do?" I was Mr. Idealism, and said, "I would return it [the call]; if it's 10 more minutes of work, fine-I'll do it. That's what I'm here for. This is my job and I've chosen it." I am so glad that on my sub-i, when I was post-call and 10 minutes out of the hospital, I didn't get the page, because I wouldn't have wanted to deal with it. It's just a function of sleep [deprivation].

“I Have Trouble Blaming Them:" Reluctance to Make Moral Judgments. A striking corollary to understanding residents was the overwhelming reluctance (30 out of 33 students) to make moral judgments about residents who discussed patients in pejorative ways. One 26-year-old female medicine subintern said:

I think that in terms of working incredibly hard, it's unrealistic to think that they're not going to say insulting things to a patient at times and laugh about it... I have trouble blaming people for doing whatever it is they do.

A 25-year-old female pediatrics subintern explained why she thought a resident made what the team considered to be a tasteless joke about a family:

The reason that none of us really felt that terrible about it is because she was exhausted and post-call. You can't take anything she says seriously.

A 23-year-old male medicine clerk explained:

You might say that the benefit [of the humor and slang] outweighs any kind of negative connotations that would go along with treating another person's problems in a less than compassionate way.

A 25-year-old medicine subintern explained why the term "gomer" was not as bad as other derogatory humor she had heard, because the medicine residents who she respects use this term:

So I kind of don't want to condemn them [the interns] as much. It goes back to who your role models are, and I have heard my role models use that word. In some ways, it doesn't hit me as hard, because I've heard people I really respect use that word.

A 26-year-old medicine subintern grudgingly accepted this humor as inevitable:

They [the residents] are wonderful and very humane people, but they inevitably adopted the same terminology regardless of whether they thought it was good or bad.

Finally, a male medicine subintern said:

There are a lot of people who are actually really great with patients, who still occasionally make not-sosensitive comments about patients. I guess it's something that happens when people are under stress.

Despite their reluctance to judge residents, 5 students said they were disappointed in the residents. They expected 
the residents to be more caring and empathic towards the patients and to be better role models. For example, a 24year-old female surgery clerk was disappointed in derogatory humor in the operating room because "you are supposed to learn from these people [the surgeons] as experts." Another 25-year-old female medicine subintern said:

Residents who act that way when there are interns around are just being horrible role models for how you should treat your patients.

\section{More of the Insider's Perspective: Participation}

At some point students begin to participate, if only peripherally, in the humor and slang. When students spoke about their own participation, a few different responses became apparent. First, students are reluctant to join in and use medical humor, and frequently predict that they will resist. Second, students are aware that at times they do participate in the humor. Third, they feel guilty about engaging in humor that may contradict their own moral codes or do not represent the way physicians, as professionals, should talk about their patients.

Twelve students professed a reluctance to participate in the derogatory humor and slang. One 24-year-old male medicine clerk said:

I don't think I'm going to change as I become an intern. I don't think I want to get in the habit of making negative comments about the patients. I do occasionally laugh and stuff.. . But I don't like the term "brick."

Other students expressed reservations about this behavior by hoping, rather than predicting, that they would not participate in the humor and slang. A 25-year-old female surgery subintern said:

There are a lot of things going on in the hospital that shouldn't be said, and I think that initially you feel that way, and then you fall into the trap as well, and it probably just gets worse, which is the scary thing.

Another 24-year-old surgery clerk expressed her concern about developing a "cavalier attitude" and about "going downhill" over the course of her training.

Although students were often worried about participating in the humor, 10 students were aware that they had participated. A 27-year-old male medicine clerk said:

I'm as guilty as the next guy. To be accepted, in order to feel part of the team, I've occasionally been talking about patients or laughing at jokes whether they're funny or not.

One male medicine subintern went so far as to label students' participation as getting "indoctrinated into the language and culture." Other students shared this opinion and argued that it is inevitable that students will act and talk this way when they are residents.

Twelve students not only noticed their own participation in the humorous situations, but expressed some reservation or guilt about it. One such student, a 25year-old pediatrics subintern said:

I never thought I was going to refer to other people's mothers as "mom," because I find it tremendously annoying. And I do it. I did it, frankly because it was just too much trouble to insert the phrase, "the patient's mom." But I hate it.

Another student, a 26-year-old surgery clerk, told of an operating room scene in which a patient's enormous fat pad was lifted up from the operating field on a set of what looked like meat hooks:

\begin{abstract}
Everyone in the operating room had to go by and gawk. It was really like a side show. It was scary. But, of course, I was one of the people who walked by. I was like, oh I have to see this. So I think that's kind of frightening, when you find yourself participating in those kinds of... It's not really humor, but I feel like that was the kind of humor that went on in the surgery. It was making fun of people. It made me feel kind of scummy afterwards, that I actually participated in making fun of someone who was defenseless.
\end{abstract}

\section{DISCUSSION}

The above perspectives show initial reactions to hospital humor as well as judgments of its appropriateness. In the "outsider's perspective," students describe the rules of appropriate usage as determined by house staff and by attending physicians. Students describe themselves as outside of the main drama taking place during these stories. As newcomers to the wards, they sensed that they were not supposed to initiate humor at the expense of patients or use ribald slang that made them appear cynical. Although students are not supposed to participate in the joking, they are expected to appreciate the humor, and to not speak up against it, whatever their personal feelings about the humor might be. The fact that only three attending physicians were noted to have explicitly condemned this behavior may reflect the exclusion of attendings from the humor, or perhaps implicit approval.

In the "insider's perspective," we see that students generally think that this humor and slang is not appropriate, but many think that it is at times acceptable. Students gain an understanding of what life is like for residents and are able to express why they think these physicians use humor and slang at the expense of patients. Students point to the difficult lifestyle of residents as justification. It is evident through these responses that if a greater good is being served, i.e., residents are helped to cope, then students partially accept otherwise objectionable behavior.

In addition to this tacit acceptance, students are unwilling to judge the residents because they respect them as nice people who take good care of their patients. The students seem to sense that there is a discrepancy between the residents' values and their language, making their language less deplorable. Other factors may have made it difficult for students to judge. For example, students may 
have been unwilling to judge people who were older, who were at a higher level in the medical hierarchy, and who were evaluating them. Also, students may have not have wanted to judge physicians whose level of experience in the medical world was so far beyond their own. Finally, an unspoken rule of physicianhood strongly discourages condemning one's own peers, making it difficult to "whistle blow." Despite some students who were unwilling to judge, others thought the language not only objectionable, but not justifiable, i.e., because it is derogatory and cynical, and because residents set a bad example for impressionable students. These students were upset by the behavior of physicians whom they had initially identified as role models.

In comparison to their appropriateness judgments, students' "reactions" to the humor and slang were difficult to categorize. The reactions ranged from nonchalance, to shock, to apprehension and stress. These last reactions were particularly apparent in the section on "participation," as students worried about "fall[ing] into the trap as well," and developing a "cavalier attitude," and felt guilty about taking part in the behavior.

\section{Limitations}

This study has several weaknesses and strengths common to qualitative research. Thirty-three informants from one university, all interviewed by a single investigator, with a potential desire on the students' part to appear morally upright, potentially threaten the validity and generalizibility of the study. To address validity concern, we had other investigators review the interviewer's style and interviewing technique during the study itself. We initiated the interviews evenhandedly, inquiring about general as opposed to "inappropriate" humor. Students did discuss positive as well as negative reactions to clinical humor, and their tendency to judge derogatory humor leniently was a robust observation. As to generalizibility, we can offer no firm assurances but do note that our findings are in accord with previous descriptive reports of clinical humor and slang. ${ }^{2,3,13}$

\section{Implications}

Students are willing to justify and forgive much hospital humor and slang. This forgiveness likely reflects the powerful socialization forces of the hospital culture. But witnessing hospital humor and slang may enhance and exacerbate tensions that are already an inevitable part of medical school training for many students. ${ }^{14}$ Students are at times the victims of the humor. Also, they may be stressed by the dichotomy between their previous ideals and the reality of what they experience on the wards, disillusioned by their supposed role models. Finally, they must deal with their guilt and misgivings about participating in this behavior. In light of the potentially negative effects of derogatory humor and slang on medical students, this phenomenon requires greater attention. We suggest the following steps:

Focus on Work Conditions and Alternative Ways of Coping. Attempting to banish this behavior would be fruitless and impractical. Rather, we need to address the underlying reasons why it exists in the first place. Humor and slang as defense mechanisms have been described by others. $^{2}$ Mizrahi offers complex explanations for why resident attitudes towards patients are often adversarial and points largely to the frustrations embedded in housestaff education. ${ }^{15}$ Students in this study strongly echo the justification found in the literature that residents use this language and humor as a coping mechanism. Addressing problems like sleep deprivation and work hours is an important step. Showing that these factors can have an indirect effect on the professional development of students may give more ammunition to this effort. But because the stresses of being a physician go beyond the work conditions, it is also crucial to help students and house officers develop more constructive ways to cope with the daily frustrations and sadness of taking care of sick patients.

Work on "Ethical Debriefings" for Medical Students. Many medical educators have suggested and implemented ways to ease students into the ethical milieu of the hospital, such as through small group discussion sessions. ${ }^{14,16}$ This paper provides ammunition for these efforts. In these sessions, educators can help students examine the process of entering hospital-based culture and work on developing specific skills to be armed with when confronting uncomfortable situations. Importantly, these skills should help students feel more confident about judging acts as inappropriate and include discussions about the difference between judging acts and judging people. Attending physicians may be in a particularly strong position to educate students about these issues, given their clinical credibility. Discussions of appropriate and inappropriate hospital humor may deserve to be routine components of attending rounds, especially when examples of inappropriate humor surface.

Remind House Officers that They Are Role Models. In the process of "mimetic identification,"17 students ease into the role of physician by imitating house officers and attending physicians. Because of the structure of an inpatient team, students spend the most time with house officers, who often become the role models from whom students learn survival skills, ${ }^{18}$ values, and behavior implicit in the "hidden curriculum." 19 It makes sense that students are unwilling to judge residents because they want, and need, to become more like these physicians. House officers need to be reminded that they are role models and that students are watching and imitating their actions and language, which have consequences beyond the acts themselves. 
IRB approval was obtained for this study.

We would like to acknowledge Renee Fox, Chris Feudtner, and Ronald Epstein for their helpful comments on earlier drafts of this paper.

Dr. Parsons was the recipient of a National Institute of Mental Health/Measey Foundation grant. Dr. Ubel is a Robert Wood Johnson Foundation Generalist Physician Faculty Scholar and recipient of a career development award in health services research from the Department of Veterans Affairs. This research was supported in part by the Greenwall Foundation.

\section{REFERENCES}

1. Shem S. The House of God. New York, NY: Richard Marek Publishers; 1978.

2. Coombs RH, Chopra S, Schenk DR, Yutan E. Medical slang and its functions. Soc Sci Med. 1993;36:987-98.

3. George V, Dundes A. The gomer: a figure of American hospital folk speech. J Amer Folklore. 1978;91:568-81.

4. Leiderman DB, Grisso J-A. The gomer phenomenon. J Health Soc Behav. 1985;26:222-3.

5. Goffman E. The Presentation of Self in Everyday Life. Garden City, NJ: Anchor-Doubleday; 1959.

6. Hughes EC. The Sociological Eye: Selected Papers on Work, Self and Society. Chicago, Ill: The University of Chicago Press; 1971.

7. Becker HS, Geer B, Hughes EC, Strauss AL. The Boys in White: Student Culture in Medical School. Chicago, Ill: The University of Chicago Press; 1961.
8. Donnelly WJ. Medical language as symptom: doctor talk in teaching hospitals. Perspect Biol Med. 1986;30:81-94.

9. Schwarz H. A person is a person and a shpos is not. Man Med. 1980;5:226-8.

10. Feudtner C, Christakis D, Christakis NA. Do clinical clerks suffer ethical erosion? Students' perceptions of their ethical environment and personal development. Acad Med. 1994;69:670-9.

11. Brim JA, Spain DH. Research Design in Anthropology: Paradigms and Pragmatics in the Testing of Hypotheses. New York: Holt, Rinehart and Winston; 1974.

12. Pope C, Mays N. Reaching the parts other methods cannot reach: an introduction to qualitative methods in health and health services research. BMJ. 1995;311:42-5.

13. Van McCrary S, Christensen RC. Slang 'On Board'. Arch Fam Med. 1993;2:101-5.

14. Andre $J$. Learning to see: moral growth during medical training. $J$ Med Ethics. 1992;18:148-52.

15. Mizrahi T. Getting Rid of Patients: Contradictions in the Socialization of Physicians. New Brunswick, NJ: Rutgers University Press; 1986.

16. Hahn SR, Croen LG, Kupfer R, Levin G. A method for teaching human values in clinical clerkship through group discussion. Teach Learn Med. 1991;3:143-50.

17. Lief HI, Fox RC. Training for detached concern in medical students. In: Lief HI, ed. The Psychological Basis of Medical Practice. New York, NY: Hoeber Medical Division, Harper and Row; 1963:12-35.

18. Konner M. Becoming a Doctor: A Journey of Initiation in Medical School. New York, NY: Viking; 1987.

19. Hafferty FW, Franks R. The hidden curriculum, ethics teaching, and the structure of medical education. Acad Med. 1994;69: 861-71. 